\title{
Effect of Short-Term Maximal Exercise on BNP Plasma Levels in Healthy Individuals
}

\author{
J. KRUPIČKA ${ }^{1}$, T. JANOTA ${ }^{1}$, Z. KASALOVÁ ${ }^{1}$, J. HRADEC ${ }^{1}$ \\ ${ }^{1}$ Third Department of Internal Medicine, First School of Medicine and University General Hospital, \\ Charles University in Prague, Prague, Czech Republic
}

Received February 23, 2009

Accepted August 21, 2009

On-line November 20, 2009

\begin{abstract}
Summary
Many studies documented the relationship between elevated plasma concentrations of natriuretic peptides and cardiovascular diseases, especially heart failure. However, it is still uncertain whether physical exercise leads to a significant release of natriuretic peptide in healthy subjects. The aim of this study was to determine the effect of maximal physical activity on plasma BNP concentrations in healthy individuals within 3 hours after the short-term exercise. BNP plasma concentrations were measured in 15 healthy volunteers before, immediately after as well as 1 hour and 3 hours after bicycle spiroergometry. Maximal workload and exercise capacity were assessed in watts, wattseconds, metabolic equivalents and $\mathrm{VO}_{2 \max }$. Mean BNP plasma levels before, immediately after, 1 hour and 3 hours postexercise were $19.4 \pm 2.5 ; 30.6 \pm 4.7 ; 17.9 \pm 2.5$ and $18.7 \pm 3.1$ $\mathrm{pg} / \mathrm{ml}$, respectively. The increase of BNP concentrations immediately after exercise was statistically significant $(p=0.0017)$ compared to baseline values. We did not find any correlation between the post-exercise increase of BNP levels and age, body mass index, maximal workload or exercise capacity. In conclusion, short-term maximal physical exercise in healthy individuals led to a fast and transient rise of plasma BNP concentrations, which remained well within normal range and far below the cut-off value for heart failure $(100 \mathrm{pg} / \mathrm{ml})$.
\end{abstract}

\section{Key words}

Brain natriuretic peptide - Exercise test - Spiroergometry • Exercise physiology

\section{Corresponding author}

J. Krupička, Third Department of Internal Medicine, University General Hospital, U Nemocnice 1, 12808 Prague 2, Czech Republic. E-mail: j.krupicka@centrum.cz
Natriuretic peptides are synthesized and secreted by myocardium in response to increased wall stress during volume and/or pressure overload (Levin et al. 1998, Krupička et al. 2009). With regard to this fact, brain natriuretic peptide (BNP) and its aminoterminal propeptide (NT-proBNP) became valuable biomarkers for heart failure diagnosis and prognosis in clinical practice. Increased plasma concentrations of natriuretic peptides were also found in patients with acute coronary syndromes, even in those without myocardial necrosis or accompanying heart failure (de Lemos et al. 2001). Several studies have documented that transient ischemia induced by exercise stress testing triggers the release of BNP and NT-proBNP (Foote et al. 2004, Sabatine et al. 2004). Moreover, elevated natriuretic peptide levels were detected in marathon runners. In almost one third of them increased levels did not fall into normal range within 3 hours after running (Herrmann et al. 2003). As far as we know, response of natriuretic peptides to short-term physical exercise in healthy individuals has not yet been studied in detail. We hypothesized that sympathetic activation leading to increased blood pressure, heart rate and left ventricular filling pressures during the exercise test will cause BNP secretion. To test this hypothesis we examined plasma BNP levels before, immediately after as well as 1 hour and 3 hours after maximal exercise stress testing by bicycle spiroergometry. Better knowledge of BNP behavior under physiological conditions should be useful for proper assessment of load in athletes as well as for correct interpretation of BNP results after physical exercise. 
Table 1. Basic clinical characteristics and cardiopulmonary exercise test variables.

\begin{tabular}{|c|c|}
\hline Age (years) (median) & $28(25-48)$ \\
\hline Gender (\% of men) & 73 \\
\hline Body weight (kg) & $75.8 \pm 2,6$ \\
\hline Body mass index $\left(\mathrm{kg} \mathrm{m}^{-2}\right)$ & $23.3 \pm 0.6$ \\
\hline Plasma creatinine $\left(\right.$ umol $\left.l^{-1}\right)$ & $77.4 \pm 2.5$ \\
\hline HR at rest (bpm) & $78.3 \pm 2.8$ \\
\hline$B P$ at rest $(m m H g)-$ systolic & $116.2 \pm 3.5$ \\
\hline - diastolic & $74.9 \pm 2.4$ \\
\hline Maximal HR (bpm) & $178 \pm 2$ \\
\hline Achieved $\geq 90 \%$ predicted max. HR (\%) & 100 \\
\hline Maximal BP (mm Hg) - systolic & $180 \pm 5$ \\
\hline - diastolic & $92 \pm 5$ \\
\hline Peak workload $(W)$ & $247 \pm 9$ \\
\hline Peak $\mathrm{VO}_{2}\left(\mathrm{ml} \mathrm{min}{ }^{-1} \mathrm{~kg}^{-1}\right)$ & $43.5 \pm 2.1$ \\
\hline Achieved METS & $12.4 \pm 0.6$ \\
\hline Exercise capacity $\left(W s 10^{3}\right)$ & $105.9 \pm 9.2$ \\
\hline Indexed exercise capacity (W $\left.\mathrm{kg}^{-1} 10^{3}\right)$ & $1.3 \pm 0.1$ \\
\hline
\end{tabular}

BP - blood pressure; HR - heart rate; METS - metabolic equivalents; $\mathrm{VO}_{2}$ - oxygen uptake. Values are expressed as means \pm S.E.M.

Altogether 15 healthy volunteers (11 males and 4 females) with median age of 28 years (25-48), who did sport recreationally, were enrolled into the study after signing an informed consent. Their basic clinical characteristics are summarized in Table 1. All of the participants had normal resting electrocardiogram and echocardiogram and they did not use any medication at the time of the study. Symptom-limited exercise was performed by bicycle spiroergometry (VIASYS Healthcare, California, USA) using a protocol, which began with a workload of $100 \mathrm{~W}$ increasing gradually by $50 \mathrm{~W}$ every $2 \mathrm{~min}$. Oxygen uptake and other respiratory parameters (minute ventilation, carbon dioxide output) were measured at rest and during the exercise. Venous blood samples were obtained before, immediately after, 1 hour and 3 hours after the stress test, respectively. Samples were placed in ethylenediaminetetraacetic acid anticoagulated tubes and analyzed within one hour using a chemoluminescent immunoassay (Bayer, Germany). All data are expressed as a mean \pm S.E.M. for numerical variables. Only for age median, minimal and maximal values were used. The repeated Student t-tests with Bonferroni adjustment were used for comparison between groups. Correlations were evaluated by the Pearson's correlation test. All calculations were performed using commercially available statistical software
(STATISTICA Cz 6, StatSoft, Czech Republic). The Bonferroni-adjusted value of $\mathrm{p}<0.0083$ was considered to be significant.

All of the 15 examined healthy individuals reached at least $90 \%$ of their target calculated maximal heart rate during the stress test. Mean achieved workload (W), METS and peak $\mathrm{VO}_{2}\left(\mathrm{ml} \mathrm{min}^{-1} \mathrm{~kg}^{-1}\right)$ were $247 \pm 9$, $12.4 \pm 0.6$ and $43.5 \pm 2.1$, respectively. No cases of serious arrhythmia, marked ischemia, chest pain or severe hypertension were detected. Summary of exercise test data are showed in Table 1. Mean pre-exercise BNP level was $19 \pm 2.5 \mathrm{pg} / \mathrm{ml}$. Mean BNP plasma level increased significantly immediately after the stress test to $31 \pm 4.7 \mathrm{pg} / \mathrm{ml}(\mathrm{p}=0.0017)$. One hour as well as 3 hours after the end of exercise mean BNP concentrations did not differ significantly from the baseline values $(18 \pm 2.5 \mathrm{pg} / \mathrm{ml}$ and $19 \pm 3.1$, respectively) (Fig. 1). The rise of BNP immediately after the exercise did not correlate with basic demographic characteristics of the participants (gender, age, body mass index) as well as with any measured clinical, respiratory or exercise test-derived variables.

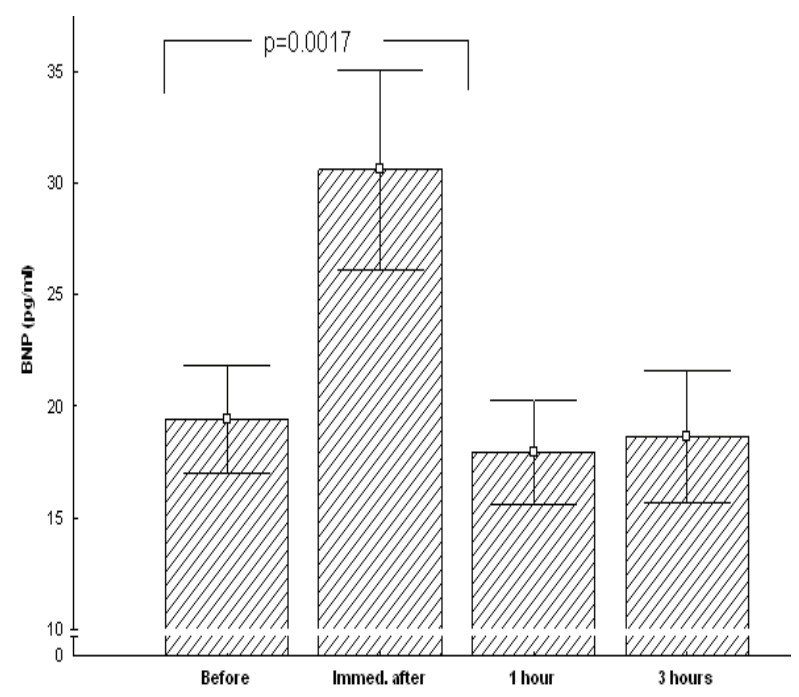

Fig. 1. Bar graph showing brain natriuretic peptide (BNP) levels before, immediately after (immed.), 1 hour and 3 hours postexercise. Values are expressed as means \pm S.E.M.

It is well known from animal experiments that increased myocardium wall stress rapidly triggers synthesis and release of natriuretic peptides (Magga et al. 1994). Magga et al. (1994) measured BNP mRNA and plasma BNP during pressure overload in rats. Natriuretic peptide gene expression followed by increased plasma BNP levels started within 1 hour and peak BNP values 
were detected at 4 hours after the intervention. Therefore, it could be possible that BNP plasma concentrations will increase after short-term exercise also in healthy subjects. To test this hypothesis we performed our study with 15 healthy volunteers. We found that even short-term exercise induced surprisingly prompt and significant increase of plasma BNP concentrations. However, this change was well within normal ranges and BNP in no case reached pathological values typical for cardiovascular diseases. Several studies documented the relationship between natriuretic peptides rise and the severity of ischemia during exercise stress testing in patients with coronary artery disease (Foote et al. 2004, Sabatine et al. 2004). Another study described the exercise induced elevation of plasma BNP levels in patients with chronic heart failure (Kato et al. 2000). Very recently, Wozakovska-Kapłon et al. (2009) observed increase of BNP plasma levels after treadmill ergometry in patients with atrial fibrillation. This was in contrast with controls, where BNP remained almost unchanged. Nevertheless, the reports on natriuretic peptide response to exercise in healthy individuals are controversial. Sabatine et al. (2004) reported that plasma levels of BNP and NT-proBNP in subjects without ischemia during exercise did not change significantly within 4 hours after stress testing. On the other hand,
Kato et al. (2000) reported small but significant increase of BNP values in healthy volunteers immediately after exercise. To explain these discrepancies is not easy. The reason can be in different study design, subjects characteristics, exercise test protocol, etc. For example, our subjects were healthy similarly to the control subjects in the study of Kato et al. (2000). Sabatine et al. (2004) studied individuals with suspected coronary artery disease. Their mean workload was substantially lower than that in our study. We also found that BNP fell to baseline values within one hour after the end of the exercise. Our finding is in contrast with constitutive manner of BNP synthesis and secretion (Hall 2004). The feasible mechanism explaining the observed transient BNP rise could be a release of BNP from cardiomyocyte storage granules caused by increase in left ventricular wall stress during short-term maximal physical exercise. On the other hand, long-lasting intensive physical activity, such as long-range athletic races, could trigger cardiomyocytes BNP gene expression and synthesis de novo. To confirm this hypothesis, additional studies need to be performed.

\section{Conflict of Interest}

There is no conflict of interest.

\section{References}

DE LEMOS JA, MORROW DA, BENTLEY JH, OMLAND T, SABATINE MS, MCCABE CH, HALL C, CANNON CP, BRAUNWALD E: The prognostic value of B-type natriuretic peptide in patients with acute coronary syndromes. $N$ Engl J Med 345: 1014-1021, 2001.

FOOTE RS, PEARLMAN JD, SIEGEL AH, YEO K-TJ: Detection of exercise-induced ischemia by changes in B-type natriuretic peptides. J Am Coll Cardiol 44: 1980-1987, 2004.

HALL C: Essential biochemistry and physiology of (NT-pro)BNP. Eur J Heart Fail 6: 257-260, 2004.

HERRMANN M, SCHARHAG J, MICLEA M, URHAUSEN A, HERRMANN W, KINDERMANN W: Post-race kinetics of cardiac troponin $\mathrm{T}$ and $\mathrm{I}$ and $\mathrm{N}$-terminal pro-brain natriuretic peptide in marathon runners. Clin Chem 49: 831-834, 2003.

KATO M, KINUGAWA T, OGINO K, ENDO A, OSAKI S, IGAWA O, HISATOME I, SHIGEMASA C: Augmented response in plasma brain natriuretic peptide to dynamic exercise in patients with left ventricular dysfunction and congestive heart failure. $J$ Intern Med 248: 309-315, 2000.

KRUPIČKA J, JANOTA T, KASALOVÁ Z, HRADEC J: Natriuretic peptides - physiology, pathophysiology and clinical use in heart failure. Physiol Res 58: 171-177, 2009.

LEVIN ER, GARDNER DG, SAMSON WK: Natriuretic Peptides. N Engl J Med 339: 321-328, 1998.

MAGGA J, MARTTILA M, MANTYMAA P, VUOLTEENAHO O, RUSKOAHO H: Brain natriuretic peptide in plasma, atria, and ventricles of vasopressin- and phenylephrine-infused conscious rats. Endocrinology 134: 2505-2515, 1994. 
SABATINE MS, MORROW DA, DE LEMOS JA, OMLAND T, DESAI MY, TANASIJEVIC M, HALL C, MCCABE CH, BRAUNWALD E: Acute changes in circulating natriuretic peptide levels in relation to myocardial ischemia. J Am Coll Cardiol 44: 1988-1995, 2004.

WOZAKOVSKA-KAPŁON B, OPOLSKI G: Effects of exercise testing on natriuretic peptide secretion in patients with atrial fibrillation. Kardiol Pol 67: 254-261, 2009. 